\title{
Improved DTC strategy of an electric vehicle with four in-wheels induction motor drive 4WDEV using fuzzy logic control
}

\author{
Nair Nouria, Gasbaoui Brahim, Ghazouani Abdelkader, Benoudjafer Cherif \\ Department of Technology, University of Tahri Mohammed, Smart Grids \& Renewable Energies Laboratory, \\ Bechar, Algeria
}

\begin{tabular}{l} 
Article Info \\
\hline Article history: \\
Received Nov 6, 2020 \\
Revised Dec 31, 2020 \\
Accepted Feb 28, 2021 \\
\hline
\end{tabular}

Keywords:

4W electric vehicle Direct torque control Direct torque fuzzy control Induction motor Lithium-ion battery

\begin{abstract}
In this paper, we will study a four-wheel drive electric vehicle (4WDEV) with two control strategies: Conventional Direct Torque Control (CDTC) and DTC based on fuzzy logic (DTFC). Our overall idea in this work is to show that the 4WDEV equipped with four induction motors providing the drive of the driving wheels controlled by the direct fuzzy torque control ensures good stability of the 4WDEV in the different topologies of the road, bends and slopes, and increases the range of the electric vehicle. Numerical simulations were performed on an electric vehicle powered by four $15 \mathrm{~kW}$ induction motors integrated into the wheels using the MATLAB/Simulink environment, where the reference speeds of each wheel (front and rear) are obtained using an Electronic Speed Differential (ESD). This can eventually cause it to synchronize the wheel speeds in any curve. The speed of each wheel is controlled by two types of PI and FLC controllers to improve stability and speed response (in terms of setpoint tracking, disturbance rejection and climb time). Simulation results show that the proposed FLC control strategy reduces torque, flux and stator current ripple. While the 4WDEV range was improved throughout the driving cycle and battery power consumption was reduced.
\end{abstract}

This is an open access article under the CC BY-SA license.

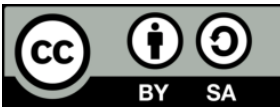

\section{Corresponding Author:}

Nair Nouria

Departement of Technology

Tahri Mohammed University

B. P 417 route Kendsa, University of Tahri Mohammed, Bechar, Algeria

Email: nouria0479@gmail.com

\section{INTRODUCTION}

Today, in the automotive sector, manufacturers are moving towards improving internal combustion engines and hybridization with electric motors to minimize $\mathrm{CO} 2$ emissions. A more ambitious alternative is to do without the internal combustion engine, and therefore so-called zero emission propulsion [1], [2]. In general, the most commonly used electric actuators in the majority of industrial applications are built around the induction motor [3], [4]. The induction motor in particular is characterized by its robustness, reliability, low cost and does not require regular maintenance. However, its dynamic behaviors are often very complex, because it's modeling results in a highly coupled nonlinear multivariate system of equations [5], [6]. Additionally, some of its state variables, including flows, cannot be measured. Different drive techniques for induction machines have been introduced to provide variable frequency speed control. Most of them are based on rigorous mathematical formalisms. Among all the control methods, DTC or direct torque control is considered particularly interesting. 
Takahashi's theory is to specifically evaluate the control pulses used for voltage reversing switches to maintain electromagnetic torque and stator flow within two predefined depenbrock hysteresis bands [7], [8]. Such an application of this technique allows decoupling of torque and flow control without the need for pulse width modulation (PWM) or coordinate transformation. Several studies are still underway to improve the main classic drawbacks of DTC. Among these drawbacks are torque ripples and stator flux [8], [9].

In this article, we mainly describe the implementation of a robust and efficient control law the DTFC, which stands for direct fuzzy torque control. Fuzzy logic is a fuzzy linguistic approach used by a type condition (Si-Then) based on the imitation of approximate qualitative aspects of human reasoning [10]. And to apply it in our work, we will study a traction system of an electric vehicle (4WDEV). The 4WDEV is equipped with four asynchronous motors ensuring the drive of the driving wheels controlled by a direct fuzzy torque control. The proposed control law ensures good stability of the 4WDEV in different road topologies, curves and slopes and increases the autonomy of the electric vehicle. The second method is introduced to replace the torque hysteresis controllers, flow rate controllers, and switch table used in the CDTC with fuzzy logic controllers. The main objective of the DTFC method is to improve the dynamic performance of electric vehicles and to reduce torque and flow ripples.

\section{DESCRIPTION OF THE 4-WHEEL DRIVE ELECTRIC VEHICLE}

In Figure 1, the 4WDEV drive train shows that the power structure of this drive train consists of four induction motors built into the wheels driven by four three-phase inverters, the principal power source for the vehicle being the lithium-ion (li-ion) battery. It is connected to the DC bus via a two-way DC-DC (Buck-Boost converter) converter. A Ghezouani [8] the four induction motors are driven by the DC bus via a DC-AC converter. The control method used for each engine is DTFC fuzzy torque control. The goal of this approach is to enhance the conventional direct torque control DTFC strategy. The rolling engines are powered by an electronic differential. This system uses the throttle position and the wheel angle, specified as inputs by the rotation of the wheel.

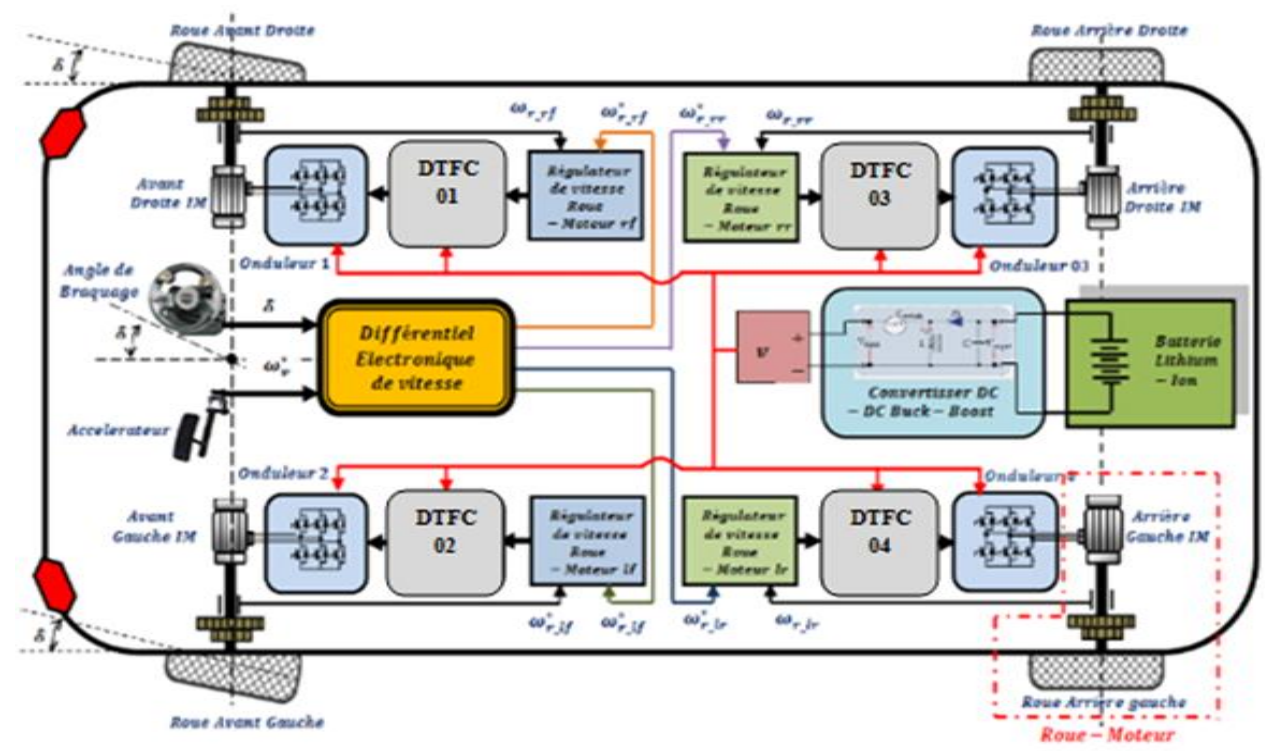

Figure 1. General structure of the EV4WD four-wheel drive electric vehicle studied

\section{LOAD BALANCE OF THE FOUR-WHEEL DRIVE ELECTRIC VEHICLE}

As shown in Figure 2, the total force Ftot required to move the electric vehicle forward is the sum of the different components resulting from the balance of the mechanical forces applied to the vehicle [8], [9]. Table 1 clarifies the concepts used (2) to (8).

$$
\mathrm{F}_{\text {tot }}=\mathrm{F}_{\text {roul }}+\mathrm{F}_{\text {aero }}+\mathrm{F}_{\text {Slope }}+\mathrm{F}_{\mathrm{acc}}=\mathrm{F}_{\mathrm{R}}+\mathrm{F}_{\mathrm{acc}}
$$

- $\quad \mathrm{F}_{\text {roul }}$ is the rolling resistance force related to the rolling coefficient of the wheels $\left(\mathrm{C}_{\mathrm{rr}}\right)$. The rolling resistance force is: $\mathrm{F}_{\text {roul }} \approx \mathrm{gM}_{\text {Scooter }} \mathrm{C}_{\mathrm{rr}}$. 
- $\mathrm{F}_{\mathrm{aero}}$ is the aerodynamic resistance force, proportional to the air density, to the square of the wind speed, to the frontal section of the vehicle and to its air penetration coefficient $\left(\mathrm{C}_{\mathrm{px}}\right)$. Its expression is given by (2).

$\mathrm{F}_{\text {aero }}=\frac{1}{2} \rho \mathrm{S}_{\mathrm{f}} \mathrm{C}_{\mathrm{px}}\left(\mathrm{V}_{\mathrm{veh}}-\mathrm{V}_{\text {wind }}\right)^{2}$

Frontal section of the vehicle and to its air penetration coefficient $\left(\mathrm{C}_{\mathrm{px}}\right)$. Its expression is given by (3).

$$
\mathrm{F}_{\text {aero }}=\frac{1}{2} \rho \mathrm{S}_{\mathrm{f}} \mathrm{C}_{\mathrm{px}}\left(\mathrm{V}_{\mathrm{veh}}-\mathrm{V}_{\text {wind }}\right)^{2}
$$

- $\mathrm{F}_{\text {pente }}$ is the resistance force of the slope to be climbed. In the case where the electric vehicle would have to climb a corner slope $\left(\alpha_{\mathrm{p}}\right)$ as shown in Figure 2, there is an additional force proportional to the total mass of the vehicle that is applied to its forward motion this force is given by:

$\mathrm{F}_{\text {pente }}=\mathrm{gM}_{\mathrm{veh}} \cdot \sin \left(\alpha_{\mathrm{p}}\right)$

$\mathrm{F}_{\mathrm{acc}}$ is the dynamic term for the acceleration or deceleration of the electric vehicle.

$$
\mathrm{F}_{\mathrm{acc}}=\mathrm{M}_{\mathrm{veh}} \frac{\mathrm{dV}_{\mathrm{veh}}}{\mathrm{dt}}=\mathrm{M}_{\mathrm{veh}} \gamma
$$

- Finally, the total effort of the vehicle's forward resistance is worth.

$$
\mathrm{F}_{\text {tot }}=\mathrm{gM}_{\mathrm{veh}} \mathrm{C}_{\mathrm{rr}}+\frac{1}{2} \rho \mathrm{S}_{\mathrm{f}} \mathrm{C}_{\mathrm{px}}\left(\mathrm{V}_{\mathrm{veh}}-\mathrm{V}_{\mathrm{wind}}\right)^{2}+\mathrm{gM}_{\mathrm{veh}} \cdot \sin \left(\alpha_{\mathrm{p}}\right)+\mathrm{M}_{\mathrm{veh}} \gamma
$$

- The wheel resistance torque $\mathrm{C}_{\mathrm{r}}$ is related to the resistance force by (7).

$\mathrm{C}_{\mathrm{r}}=\mathrm{F}_{\text {tot }} \cdot \mathrm{R}_{\omega}$

- The angular velocity $\omega_{-}(\mathrm{r}-\mathrm{i})(\mathrm{rad} / \mathrm{s})$ of each driven wheel is related to the vehicle speed by (8).

$$
\omega_{\mathrm{r}-\mathrm{i}}=\frac{\mathrm{v}_{\mathrm{veh}}}{2 \mathrm{R}_{\omega}}
$$

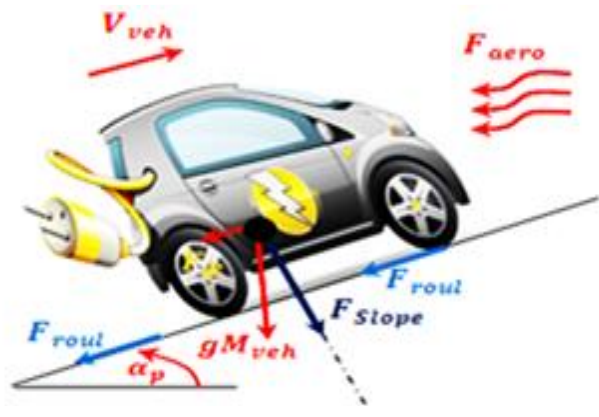

Figure 2. Forces exerted on the four-wheel drive electric vehicle
Table 1. Appearance properties of accepted

\begin{tabular}{ccl}
\multicolumn{3}{c}{ manuscripts } \\
\hline$M_{\text {veh }}$ & $\mathrm{Kg}$ & \multicolumn{1}{c}{ Total mass of the vehicle } \\
\hline$J_{\text {veh }}$ & $\mathrm{Kg} \cdot \mathrm{m}^{2}$ & Vehicle inertie \\
$V_{\text {veh }}$ & $\mathrm{m} \cdot \mathrm{s}^{-1}$ & Vehicle speed \\
$V_{\text {wind }}=0$ & $\mathrm{~m} \cdot \mathrm{s}^{-1}$ & Wind speed \\
$g=9.81$ & $\mathrm{~m} \cdot \mathrm{s}^{-2}$ & Acceleration of Gravity \\
$C_{p x}$ & & Air penetration coefficient \\
$S_{f}$ & $\mathrm{~m}^{2}$ & Front section of the vehicle \\
$\rho$ & $\mathrm{Kg} \cdot \mathrm{m}^{3}$ & Air volume Density \\
$R_{\omega}$ & $\mathrm{m}$ & Wheel radius \\
$r r$ & & Right Rear Wheel \\
$l r$ & & Left Rear Wheel
\end{tabular}

\section{THE IN-WHEEL ELECTRIC DRIVE IM MODEL}

For the elaboration of control strategies, it is necessary to find a compromise between the complexity and the accuracy of the modeling and since the objective of the present work is the direct torque control based on fuzzy logic (DTFC) based on the knowledge of the amplitude and position of the stator flux [11], [12] the complete model of the machine in the Park reference frame linked to the stator reference frame $(\alpha-\beta)(9)$ to $(12)$.

$$
\dot{x}=A x+B u
$$


such as:

$$
\begin{aligned}
& x=\left[\begin{array}{lll}
i_{s \alpha} & i_{s \beta} & \varphi_{s \alpha} \\
\varphi_{s \beta}
\end{array}\right]^{T}, u=\left[\begin{array}{ll}
u_{s \alpha} & u_{s \beta}
\end{array}\right]^{T} \\
& {\left[\begin{array}{cccc}
-\eta & \omega_{r} & K & \frac{\omega_{r}}{\sigma L_{s}} \\
\omega_{r} & -\eta & -\frac{\omega_{r}}{\sigma L_{S}} & K \\
R_{S} & 0 & 0 & 0 \\
0 & R_{S} & 0 & 0
\end{array}\right] ; B=\left[\begin{array}{cc}
\frac{1}{\sigma L_{S}} & 0 \\
0 & \frac{1}{\sigma L_{S}} \\
1 & 0 \\
0 & 1
\end{array}\right]}
\end{aligned}
$$

with:

$$
\sigma=1-\frac{M^{2}}{L_{S} L_{r}}, T_{s}=\frac{L_{S}}{R_{s}}, T_{r}=\frac{L_{r}}{R_{r}}, \omega_{r}=p \Omega_{r}, K=\frac{1}{\sigma L_{s} T_{r}}, \eta=-\frac{1}{\sigma}\left(\frac{1}{T_{r}}+\frac{1}{T_{S}}\right)
$$

\section{CONVENTIONAL DTC FOR ONE IN-WHEEL INDUCTION MOTOR DRIVE}

In the mid-eighties, I suggested a Method for the Direct Torque Control of Induction Motors (DTC) in the literature of Takahashi T [13], [14], Noguchi and Deerbrook. The DTC theory is based on a direct determination of the pulses used for the voltage inverter switches. This is done to maintain the electromagnetic torque and the stator flow in two hysteresis bands. Such application ensures that torque and flux control are disconnected.

The voltage inverter allows for 7 locations in the phase plane, which corresponds to the 8 sequences of the voltage vector at the inverter output [15], [16]. The block diagram in Figure 3 shows a synoptic DTC diagram used in a three-wheeled electric scooter inductive motor. The flux calculation can be estimated from the stator current and voltage measurements of the induction machine [17]. Table 2 shows the DTC control truth table.

$$
\begin{aligned}
& \varphi_{s \alpha}=\int_{0}^{t}\left(v_{s \alpha}-R_{s} i_{s \alpha}\right) d t \\
& \varphi_{s \beta}=\int_{0}^{t}\left(v_{s \beta}-R_{s} i_{s \beta}\right) d t
\end{aligned}
$$

The stator flux module is.

$$
\varphi_{\mathrm{s}}=\sqrt{\varphi_{\mathrm{s} \alpha}{ }^{2}+\varphi_{\mathrm{s} \beta}{ }^{2}}
$$

The $N_{i}$ field in which the vector $\varphi_{s}$ is located is determined from the components $\varphi_{s \alpha}$ and $\varphi_{s \beta}$ the angle $\theta_{s}$ between the repository $(\alpha-\beta)$ and the vector $\varphi_{s}[18]$.

$$
\theta_{\mathrm{s}}=\operatorname{arctg}\left(\frac{\varphi_{\mathrm{s} \beta}}{\varphi_{\mathrm{s} \alpha}}\right)
$$

When the two flux components are reached, the electromagnetic torque can be calculated by [19].

$$
\mathrm{T}_{\mathrm{em}}=\frac{3}{2} \mathrm{p}\left[\varphi_{\mathrm{s} \alpha} \mathrm{i}_{\mathrm{s} \beta}-\varphi_{\mathrm{s} \beta} \mathrm{i}_{\mathrm{s} \alpha}\right]
$$

Table 2. DTC control truth table

\begin{tabular}{ccccccccc}
\hline Sector $N_{i}$ & & $S_{1}$ & $S_{2}$ & $S_{3}$ & $S_{4}$ & $S_{5}$ & $S_{6}$ & \\
\hline \multirow{4}{*}{$\Delta \varphi_{s}=1$} & $\Delta T_{e m}=1$ & $\mathrm{~V}_{2}$ & $\mathrm{~V}_{3}$ & $\mathrm{~V}_{4}$ & $\mathrm{~V}_{5}$ & $\mathrm{~V}_{6}$ & $\mathrm{~V}_{1}$ \\
& $\Delta T_{e m}=0$ & $\mathrm{~V}_{7}$ & $\mathrm{~V}_{0}$ & $\mathrm{~V}_{7}$ & $\mathrm{~V}_{0}$ & $\mathrm{~V}_{7}$ & $\mathrm{~V}_{0}$ \\
& $\Delta T_{e m}=-1$ & $\mathrm{~V}_{6}$ & $\mathrm{~V}_{1}$ & $\mathrm{~V}_{2}$ & $\mathrm{~V}_{3}$ & $\mathrm{~V}_{4}$ & $\mathrm{~V}_{5}$ \\
& $\Delta T_{e m}=1$ & $\mathrm{~V}_{3}$ & $\mathrm{~V}_{4}$ & $\mathrm{~V}_{5}$ & $\mathrm{~V}_{6}$ & $\mathrm{~V}_{2}$ & $\mathrm{~V}_{1}$ \\
$\Delta \varphi_{s}=0$ & $\Delta T_{e m}=0$ & $\mathrm{~V}_{0}$ & $\mathrm{~V}_{7}$ & $\mathrm{~V}_{0}$ & $\mathrm{~V}_{7}$ & $\mathrm{~V}_{0}$ & $\mathrm{~V}$ \\
& $\Delta T_{e m}=-1$ & $\mathrm{~V}_{5}$ & $\mathrm{~V}_{6}$ & $\mathrm{~V}_{1}$ & $\mathrm{~V}_{2}$ & $\mathrm{~V}_{3}$ & $\mathrm{~V}_{4}$ \\
\hline
\end{tabular}




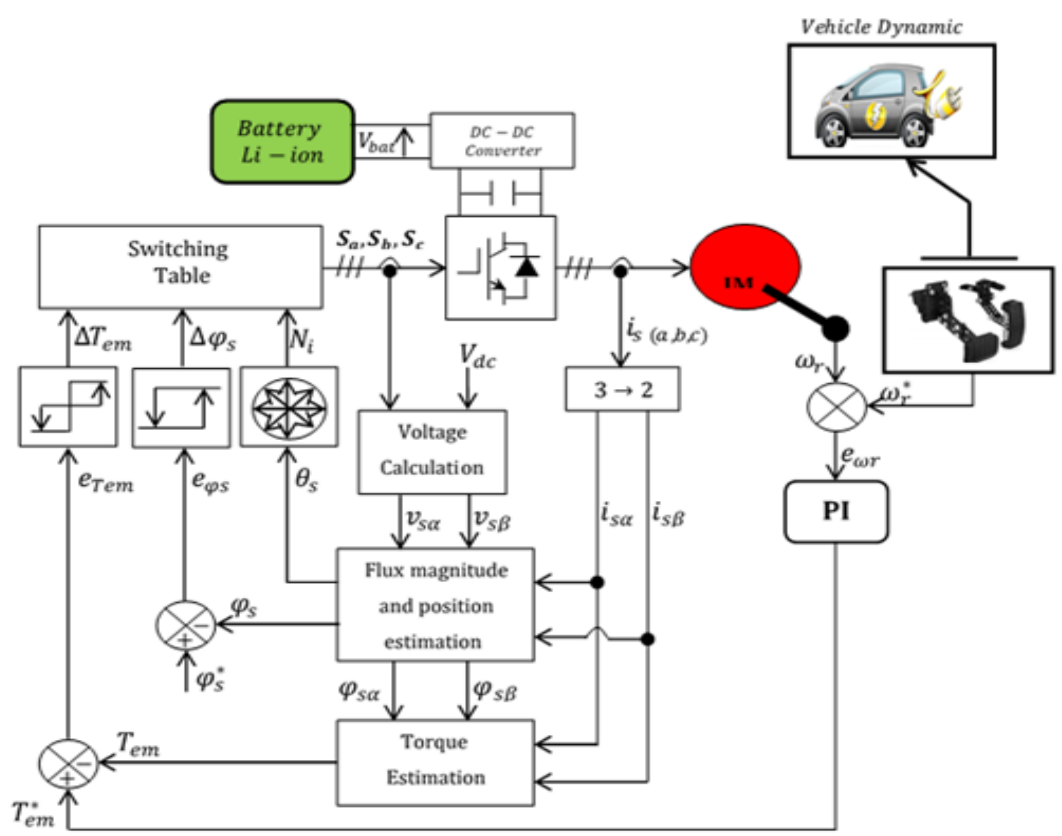

Figure 3. Conventional DTC for induction motor drive in the wheels used in the 4WDEV

\section{DIRECT TORQUE FUZZY CONTROL OF THE ASYNCHRONOUS MACHINE}

The traditional DTC control provides rapid and precise response to electromagnetic torque and stator flux. The greatest drawback of this power, however is the large torque, stator flux and current ripple due to the use of hysteresis comparators [20]. This section proposes to boost the efficiency of the traditional CDTC Control, Direct Torque Fuzzy Control (DTFC). This method proposes to replace the hysteresis comparators and the selection table with a controller based on a fuzzy inference system [21], [22]. Figure 4 shows the schematic diagram of the DTFC control of an induction motor integrated in the wheels of the fourwheel drive electric vehicle. The obtained torque $\left(\mathrm{e}_{\mathrm{Tem}}\right)$ and flux $\left(e_{\varphi s}\right)$ errors as well as the angle $\theta_{s}$ are required by the fuzzy inference system to evaluate the reference voltage vector to drive the torque and flux to their desired values.

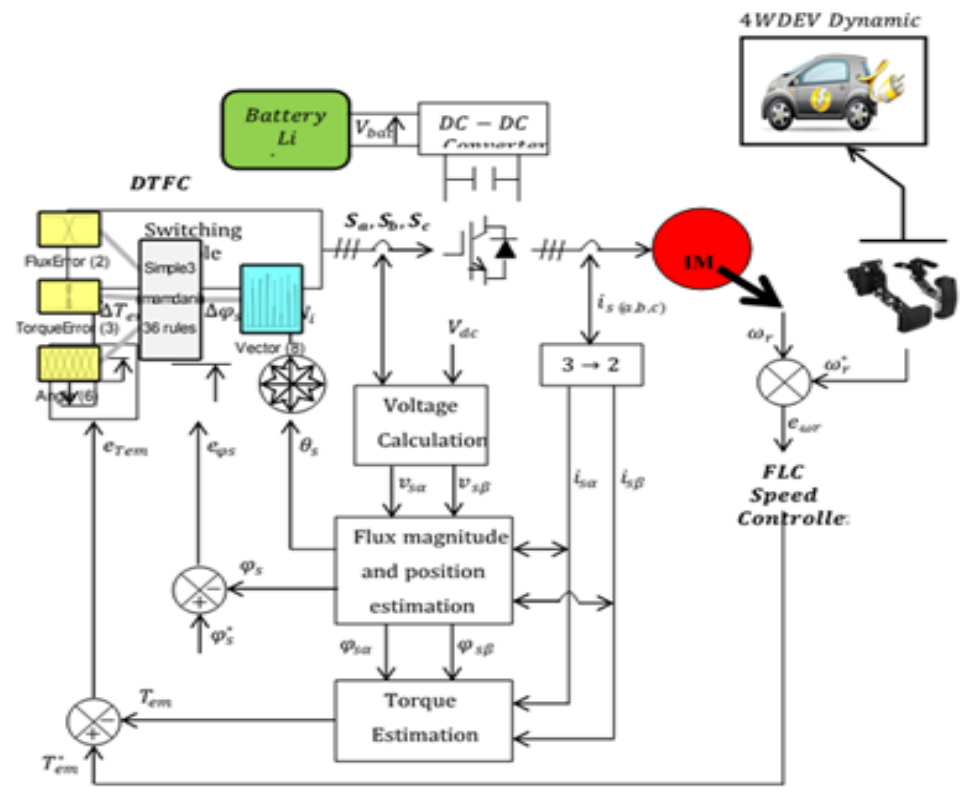

Figure 4. Schematic diagram of the direct fuzzy control (DTFC) of the MI integrated in the wheels of the EV 
Figure 5 displays the membership functions for the fuzzy inference method input and output variables. Trapezoidal and triangular association functions have been selected. The input of the torque error consists of 3 fuzzy sets $\mathrm{N}$ (negative), Z (zero) and P (positive). Two fuzzy sets were considered for the flow error membership functions, $\mathrm{N}$ (negative) and $\mathrm{P}$ (positive) [23]. The stator flux angle can be defined by six linguistic variables $\left(\theta_{1} \rightarrow \theta_{6}\right)$, to have a fine adjustment. The inferential device output variable is divided into eight individualtons, two null voltages (V0 and V7) and six null voltages. The output variable membership functions are shown in Figure 5. The different possible combinations of 3 fuzzy sets for torque error, 2 fuzzy sets for flux error and six sectors for stator flux angle form 36 rules in the basis of the inference system.
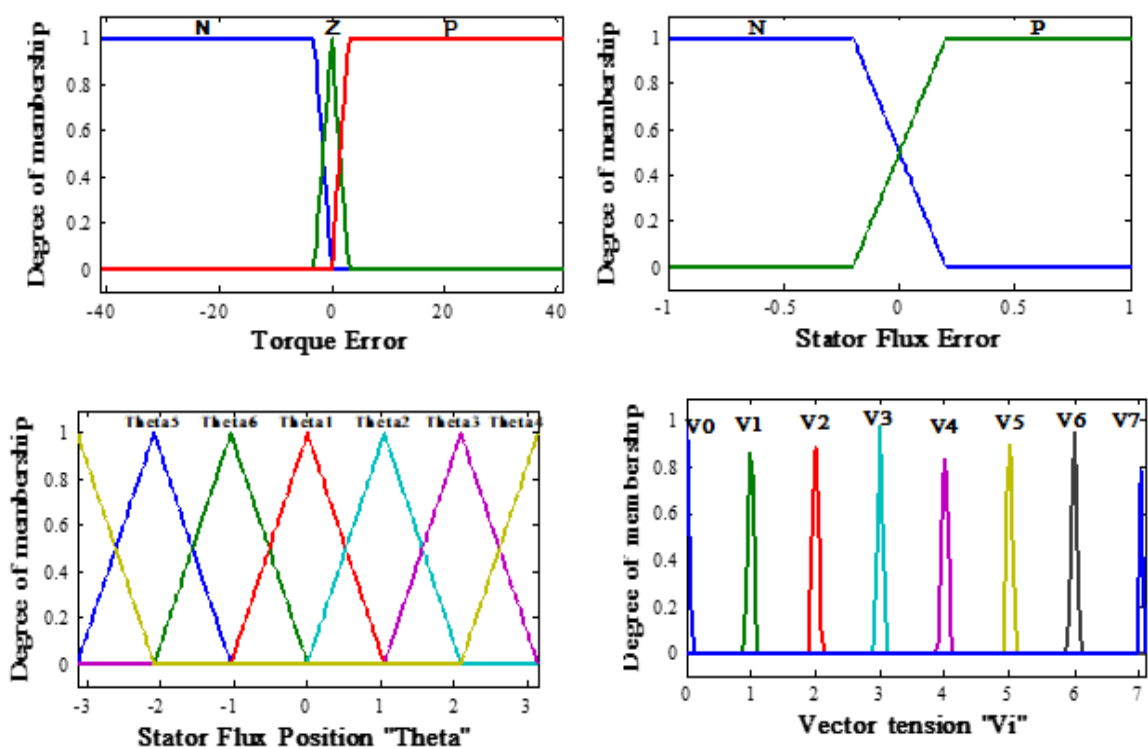

Figure 5. The membership functions for the input and output variables of the fuzzy inference system

The rule base is based on a stator flux diagram $(\alpha-\beta)$ in the plane. For example, if the angle $\theta s$ of the stator flux lies in the value of $\theta 2$ if one wants to slowly decrease the torque and quickly increase the flow then the vector V1 is the most suitable alternative. The same rationale is used to construct the rule base for the fluid direct torque control in Table 3. The laws are the fluid control inferior engine. They express in a relation between elementary fluffy proposals or conjunctions of fundamental proposals [21], [23].

$$
R_{i} \text { : if } e_{\varphi s} \text { is } A_{i} \text { and } e_{T e m} \text { is } B_{i} \text { and } \theta_{s} \text { is } C_{i} \text { then } v \text { is } V_{i}
$$

With $A_{i}, B_{i}$ and deare the linguistic variables of the flux error, the torque error and the stator flux angle, respectively. $V_{i}$ is the output linguistic variable and $R_{i}$ is rule number $\mathrm{i}$.

Table 3. Fuzzy logic switching rules

\begin{tabular}{cccccccc}
\hline $\mathrm{e}_{\varphi \mathrm{s}}$ & $\mathrm{e}_{\mathrm{Tem}}$ & $\theta_{1}$ & $\theta_{2}$ & $\theta_{3}$ & $\theta_{4}$ & $\theta_{5}$ & $\theta_{6}$ \\
\hline $\mathrm{N}$ & $\mathrm{N}$ & $\mathrm{V}_{5}$ & $\mathrm{~V}_{6}$ & $\mathrm{~V}_{1}$ & $\mathrm{~V}_{2}$ & $\mathrm{~V}_{2}$ & $\mathrm{~V}_{4}$ \\
& $\mathrm{P}$ & $\mathrm{V}_{0}$ & $\mathrm{~V}_{7}$ & $\mathrm{~V}_{0}$ & $\mathrm{~V}_{7}$ & $\mathrm{~V}_{0}$ & $\mathrm{~V}_{7}$ \\
& $\mathrm{Z}$ & $\mathrm{V}_{6}$ & $\mathrm{~V}_{4}$ & $\mathrm{~V}_{5}$ & $\mathrm{~V}_{6}$ & $\mathrm{~V}_{1}$ & $\mathrm{~V}_{2}$ \\
$\mathrm{P}$ & $\mathrm{N}$ & $\mathrm{V}_{3}$ & $\mathrm{~V}_{1}$ & $\mathrm{~V}_{3}$ & $\mathrm{~V}_{3}$ & $\mathrm{~V}_{4}$ & $\mathrm{~V}_{5}$ \\
& $\mathrm{P}$ & $\mathrm{V}_{7}$ & $\mathrm{~V}_{0}$ & $\mathrm{~V}_{7}$ & $\mathrm{~V}_{0}$ & $\mathrm{~V}_{7}$ & $\mathrm{~V}_{0}$ \\
\hline
\end{tabular}

$\alpha_{i}=\min \left(\mu_{A_{i}}\left(e_{\varphi s}\right), \mu_{B_{i}}\left(e_{T e m}\right), \mu_{C_{i}}\left(\theta_{s}\right)\right)$

By fuzzy reasoning, Mamdani's minimum process (20). 


$$
\mu_{V_{\mathrm{i}}}(\mathrm{v})=\min \left(\alpha_{\mathrm{i}}, \mu_{\mathrm{V}_{\mathrm{i}}}(\mathrm{v})\right)
$$

$\mu_{A_{i}}\left(e_{\varphi s}\right), \mu_{B_{i}}\left(e_{T e m}\right), \mu_{C_{i}}\left(\theta_{S}\right)$ and $(\mathrm{v}) \mu_{V_{i}}(v)$ designating respectively the degrees of membership of $e_{\varphi s}$, $e_{T e m}, \theta_{s}$ andt $v$ to the fuzzy sets $A_{i}, B_{i}, C_{i}$ and $V_{i}$.

In our case, the output is constituted by a set of singletons, we will apply the MAX method (21). The value corresponding to $\mu_{V_{\text {out }}}(v)$ should then be converted to a voltage vector. In the proposed fuzzy controller for defuzzification the method of the center of gravity was used. Figure 6 shows the characteristic surface of the proposed fuzzy controller, it expresses the variations of the actual value of the controller output as a function of the inputs when the latter are traversing the speech universe.

$$
\mu_{\mathrm{V}_{\text {out }}}(\mathrm{v})=\max _{\mathrm{i}=1}^{36}\left(\mu_{\mathrm{V}_{\mathrm{i}}}(\mathrm{v})\right)
$$

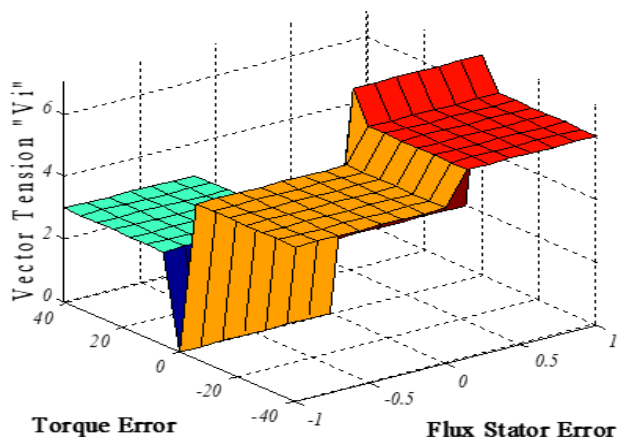

Figure 6. Characteristic surface of the fuzzy selection table

- Design of fuzzy logic speed controller

The classic PI controller has been used in speed control for the majority of different induction motor control strategies. However, the PI controller has not provided satisfactory performance in case of sudden speed changes, load torque disturbances, low speed control due to continuous variations in machine parameters and operating conditions. The refore, in order to overcome these drawbacks, controllers based on fuzzy logic are highly desirable. In this work the classical PI controller is replaced by artificial intelligence techniques, such as Fuzzy Logic Control (FLC) to improve drive performance [23, 24].

The deviation between the reference speed and the actual speed of the induction machine, $e(k)=\omega_{r}^{*}(k)-\omega_{r}(k)$, and the variation of this deviation $\Delta e(k)=e(k)-e(k-1)$, are used as fuzzy controller input fuzzy variables of the speed and the controller output is the reference electromagnetic torque $T_{e m}^{*}$, the block diagram of which is shown in Figure 7 the fuzzification of the fuzzy controller input and output variables is shown in Figure 7. Each of the three linguistic variables is represented by five fuzzy subsets ( $\mathrm{GN}=$ Large Negative, $\mathrm{PN}=$ Small Negative, $\mathrm{Z}=\mathrm{Zero}, \mathrm{PP}=$ Small Positive, GP=Large Positive). Moreover, the defuzzification has been performed by the center of gravity method associated with the sumproduct interference method [8], [25].

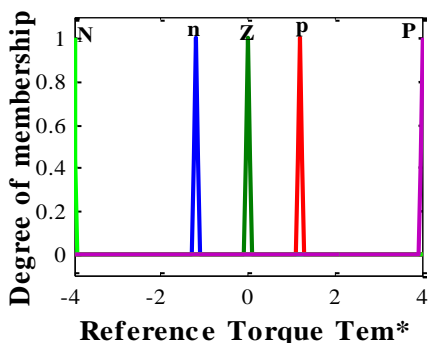

(a)

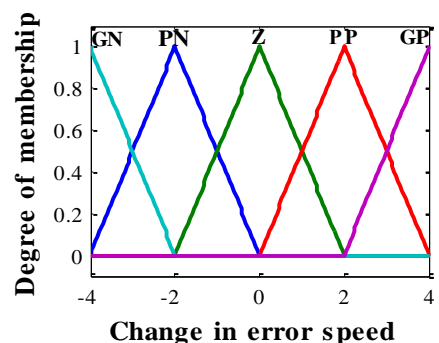

(b)

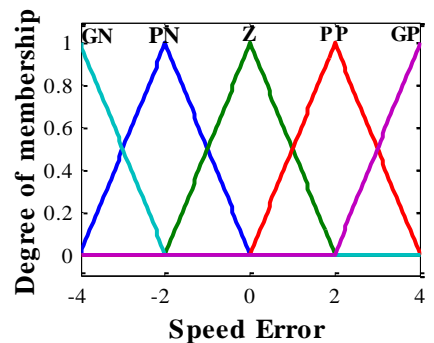

(c)

Figure 7. Functions of the FLC speed controller members for (a) the reference torque $T_{e m}^{*}$, (b) the variation of the speed error $\Delta \mathrm{e}(\mathrm{k})$ and $(\mathrm{c})$ the speed error $\mathrm{e}(\mathrm{k})$ 
Such that, for the $i^{t h}$ rule: $\mu_{c i}$ is its degree, $X_{G i}$ is the abscissa of its center of gravity and $S_{i}$ is the surface of the output fuzzy subset. The rule base for deciding the output of the inference system consists of 25 If-Then rules in this case because there are 5 fuzzy sets in each of the inputs. Table 4 shows representing the inference rule base.

$$
\Delta \mathrm{T}_{\mathrm{em}}^{*}=\frac{\sum_{\mathrm{i}=1}^{25} \mu_{\mathrm{ci}} \mathrm{X}_{\mathrm{Gi}} \mathrm{S}_{\mathrm{i}}}{\sum_{\mathrm{i}=1}^{25} \mu_{\mathrm{ci}} \mathrm{S}_{\mathrm{i}}}
$$

Table 4. Fuzzy rule

\begin{tabular}{cccccc}
\hline$e / \Delta e$ & $\mathrm{GN}$ & $\mathrm{PN}$ & $\mathrm{Z}$ & $\mathrm{PP}$ & $\mathrm{GP}$ \\
\hline $\mathrm{GN}$ & $\mathrm{N}$ & $\mathrm{Z}$ & $\mathrm{N}$ & $\mathrm{N}$ & $\mathrm{Z}$ \\
$\mathrm{PN}$ & $\mathrm{N}$ & $\mathrm{N}$ & $\mathrm{N}$ & $\mathrm{Z}$ & $\mathrm{P}$ \\
$\mathrm{Z}$ & $\mathrm{n}$ & $\mathrm{N}$ & $\mathrm{Z}$ & $\mathrm{P}$ & $\mathrm{P}$ \\
$\mathrm{PP}$ & $\mathrm{n}$ & $\mathrm{Z}$ & $\mathrm{P}$ & $\mathrm{P}$ & $\mathrm{P}$ \\
$\mathrm{GP}$ & $\mathrm{Z}$ & $\mathrm{P}$ & $\mathrm{P}$ & $\mathrm{P}$ & $\mathrm{P}$ \\
\hline
\end{tabular}

\section{PROPOSED SPEED CYCLE FOR THE 4WD ELECTRIC VEHICLE}

We have proposed a relatively short 10s speed loop to test the efficiency of the DTFC direct fuszy torque control strategy of the 4WDEV traction system, and Figure 8 presents the speed profile of the cycle. This route is characterized by seven successive phases. In the first stage, the vehicle is pushed straight at a speed of $50 \mathrm{Km} / \mathrm{h}$ in the second stage. a right turn is imposed on the vehicle by a steering angle command $\left(\delta=25^{\circ}\right)$ as shown in Figure 9, in the third phase, the 4WDEV runs on a straight road at the same speed, in the fourth phase a left turn is imposed on the vehicle with a steering angle command $\left(\delta=-15^{\circ}\right)$. The fifth phase, the vehicle runs on a straight road with a speed of $50 \mathrm{Km} / \mathrm{h}$. In the sixth phase, the VE4WD climbs an inclined road with an angle of $10^{\circ}$ (slope) with a speed of $70 \mathrm{Km} / \mathrm{h}$. Finally, the last one (7) presents the deceleration phase where the speed of the vehicle is $30 \mathrm{Km} / \mathrm{h}$. The constraints of the road are presented in Table 5 .

Table 5. Topologies of specified driving routes

\begin{tabular}{cllc}
\hline Phase & \multicolumn{1}{c}{ Time $(\mathrm{Sec})$} & \multicolumn{1}{c}{ Event information } & Véhicule speed Km/h \\
\hline 01 & $0 \mathrm{~s}<\mathrm{t}<1,5 \mathrm{~s}$ & Straight road & $50 \mathrm{~km} / \mathrm{h}$ \\
02 & $1,5 \mathrm{~s}<\mathrm{t}<2,5 \mathrm{~s}$ & Curved road SIDE right & $50 \mathrm{~km} / \mathrm{h}$ \\
03 & $2,5 \mathrm{~s}<\mathrm{t}<4 \mathrm{~s}$ & Straight road & $50 \mathrm{~km} / \mathrm{h}$ \\
04 & $4 \mathrm{~s}<\mathrm{t}<5 \mathrm{~s}$ & Curved road SIDE left & $50 \mathrm{~km} / \mathrm{h}$ \\
05 & $5 \mathrm{~s}<\mathrm{t}<6 \mathrm{~s}$ & Straight road & $50 \mathrm{~km} / \mathrm{h}$ \\
06 & $6 \mathrm{~s}<\mathrm{t}<8 \mathrm{~s}$ & Climbing slope $10 \%$ & $70 \mathrm{~km} / \mathrm{h}$ \\
07 & $8 \mathrm{~s}<\mathrm{t}<10 \mathrm{~s}$ & Straight road & $30 \mathrm{~km} / \mathrm{h}$ \\
\hline
\end{tabular}

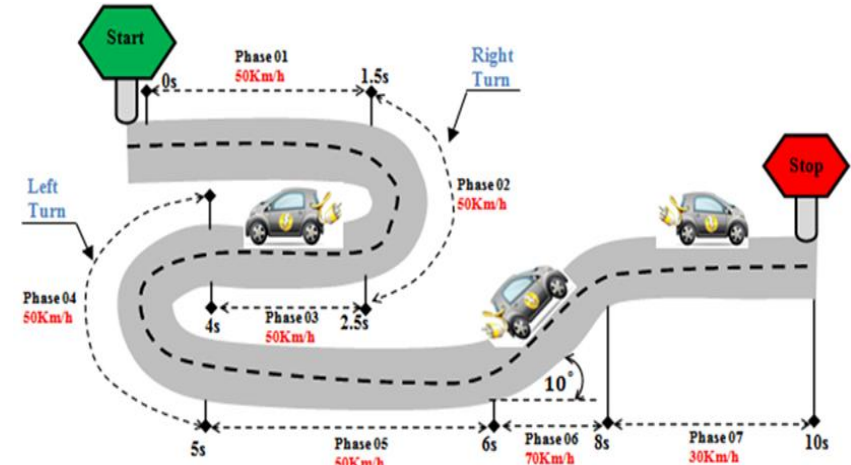

Figure 8. Specify driving road topology

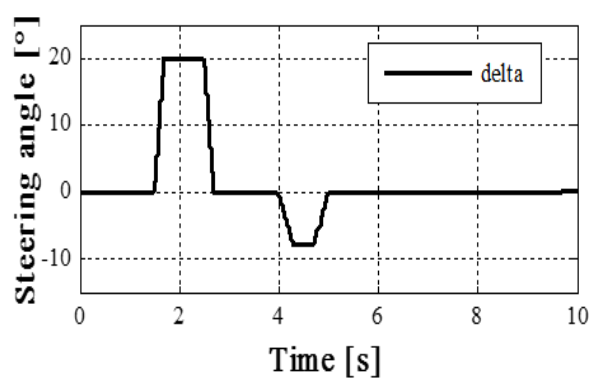

Figure 9. Steering angle variation

\section{RESULTS AND DISCUSSION}

The numerical simulations in this section were done with the MATLAB/Simulink environment on an electric vehicle drive system driven by four $15 \mathrm{~kW}$ induction motors, which were integrated in the wheels

Improved DTC strategy of an electric vehicle with four in-wheels induction motor ... (Nair Nouria) 
as shown in Figure 1. The objectives of the simulation carried out evaluated the effectiveness of the different control strategies proposed (conventional DTC and DTFC) on the dynamics of the electric vehicle, and a comparison was made between the two. This system was simulated using a reference wheel speed given by the topology shown in Figure 8. The dynamic and aerodynamic characteristics of the vehicle and Table 6 includes induction motor parameters. The aerodynamic torque is reduced with DTFC control relative to CDTC. 56.6Nm with DTFC and 57.1Nm per CDTC (phase 6, see Figure 10). This value can be explained by the large frontal zone in the case of CDTC versus DTFC. It can be seen that the overall resistive torque is improved in DTFC compared to CDTC (see Figure 11).

Table 6. Proposed 4WD electric vehicle and IM parameters

\begin{tabular}{llllll}
\hline \multicolumn{1}{c}{ Parameters Name } & \multicolumn{1}{c}{ Symbol } & Value & Parameters Name & Symbol & Value \\
\hline Wheel radius & $R_{w}(\mathrm{~m})$ & 0.32 & Rotor Inductance & $\operatorname{Lr}(H)$ & 0.149 \\
Vehicle mass & $M(\mathrm{~kg})$ & 1300 & Rotor Inductance & $\operatorname{Ls}(H)$ & 0.149 \\
Aerodynamics drag coefficient & $C_{d}$ & 0.3 & Mutual Inductance & $M(H)$ & 0.141 \\
Vehicle frontal area & $A_{f}\left(\mathrm{~m}^{2}\right)$ & 2.60 & Stator Resistance & $\operatorname{Rs}(\Omega)$ & 1.37 \\
Tirerolling resistance & $C_{r}$ & 0.01 & Rotor Resistance & $\operatorname{Rr}(\Omega)$ & 1.1 \\
coefficient & $P_{\text {air }}\left(\mathrm{kg} / \mathrm{m}^{2}\right)$ & 1.2 & Number of pole pairs & $p$ & 2 \\
Air density & $k_{\text {gear }}$ & 5 & Motor- load inertia & $J\left(\mathrm{~kg} . \mathrm{m}^{2}\right)$ & 0.1 \\
Gear coefficient & $d_{\omega}(\mathrm{m})$ & 1.5 & Rated power & $\operatorname{Pn}(\mathrm{Kw})$ & 10 \\
Width of vehicle & $L_{\omega}(\mathrm{m})$ & 2.5 & Viscous friction coefficient & $f c(N . m . s)$ & 0.00014 \\
Length of vehicle & & & & & \\
\hline
\end{tabular}

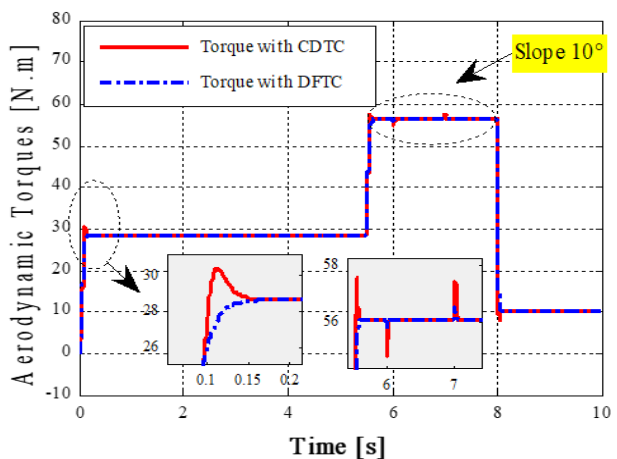

Figure 10. Vehicle Aerodynamics torque variation with CDTC and DTFC

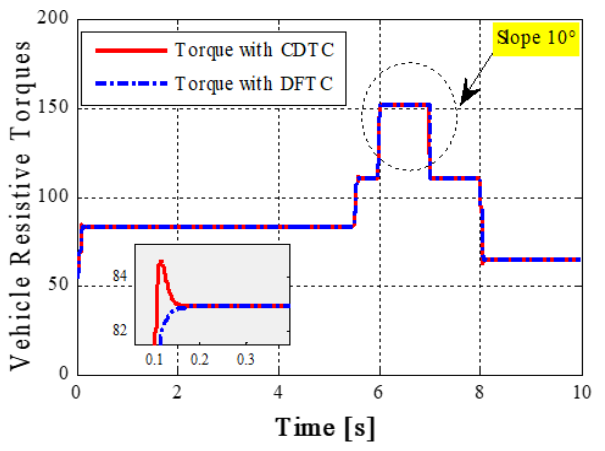

Figure 11. Globally vehicle resistive torque

The driver provides the steering angle of the front wheels; the electronic differential is centered on the speeds of the driving wheels. The speeds of the two right-hand drive wheels located on the outside of the bend (right turn phase 2) Switch at speeds greater than the two inside left drive wheels of the bend. At the moment $\mathrm{t}=4 \mathrm{~s}$ the vehicle is in the second left turn 9 (phase 4); the same thing for the electronic differential calculates the references of the new speeds to turn the wheels to stabilize the vehicle inside the left turn. Table 7 shows the speed values for each wheel for both turns (phases 2 and 4).

A Fuzzy Logic Controller (FLC) was used in place of another traditional PI type to help improve the speed response of the vehicle. The advantage of this controller lies in its robustness against speed variations and follows the setpoint without overshooting and with good accuracy. Figure 12 shows the simulation results of the linear velocity of the 4WD vehicle using the two control strategies (DTC with a PI type velocity controller and DTFC with FLC). From the results we can notice that the effect of the disturbances is clearly visible in the linear velocity response of the vehicle by using the DTC strategy (where the vehicle is driven on a $10 \%$ slope phase 6 road) with an overtaking of $0.15 \%$. The result of the two control laws can be summarized in Table 8. On the other hand, the DTFC strategy gives us a good dynamic in terms of following the instruction (setpoint) without over speeding in the stationary case with a low-rise time and zero static error.

The evolution of the four electromagnetic torque propulsion engines (IM) of the 4WD electric vehicle is given in Figure 13 (a) and Figure 13 (b), using both conventional DTC and DTFC control strategies. The results obtained illustrate quite clearly good torque response dynamic output of the proposed 
DTFC control. In addition, a significant reduction in torque ripple can be seen, compared to conventional direct torque control (DTC).

Table 7. Values of the four-wheels speed in phases 2 to 4

\begin{tabular}{lcccc}
\hline \multicolumn{1}{c}{ Wheel speed } & \multicolumn{2}{c}{ Phase 02 } & \multicolumn{2}{c}{ Phase 04 } \\
\multicolumn{1}{c}{ Km/h) } & CDTC & DTFC & CDTC & DTFC \\
\hline Front left wheel & 61,12 & 61,10 & 53,54 & 53,49 \\
Front right wheel & 55,31 & 55,25 & 51,85 & 51,80 \\
Rear left wheel & 45,35 & 45,15 & 48,35 & 48,33 \\
Rear right wheel & 39,52 & 39,43 & 47,21 & 47,19 \\
\hline
\end{tabular}

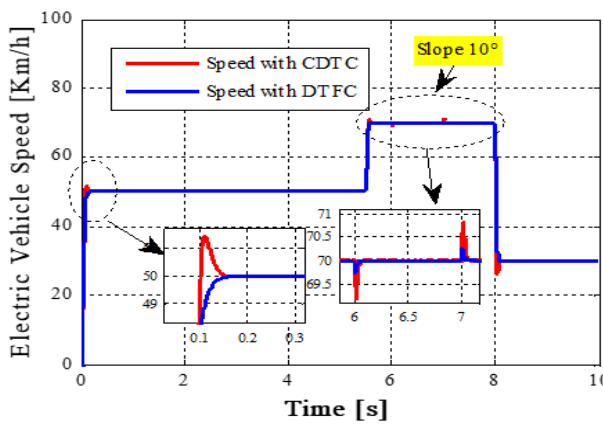

(a)
Table 8. Performances of the DTC and DTFC in the speed response

\begin{tabular}{cccc}
\hline $\begin{array}{c}\text { Control } \\
\text { Type }\end{array}$ & $\begin{array}{c}\text { Rising Time } \\
{[\mathrm{Sec}]}\end{array}$ & $\begin{array}{c}\text { Over shoot } \\
{[\%]}\end{array}$ & $\begin{array}{c}\text { Speed Error } \\
{[\%]}\end{array}$ \\
\hline DTC & 0.16 & 0.15 & 0.01 \\
DTFC & 0.11 & 0 & 0 \\
\hline
\end{tabular}

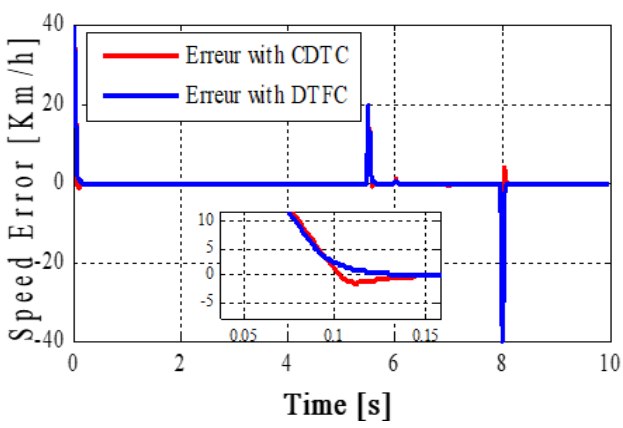

(b)

Figure 12. Vehicle Variance of linear speed (a) and error rate (b) at various points
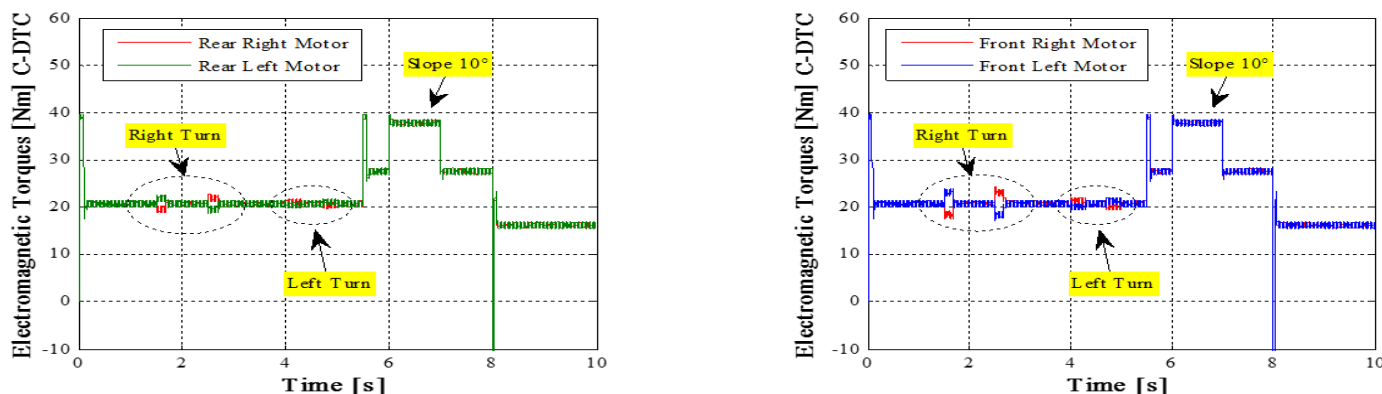

(a)
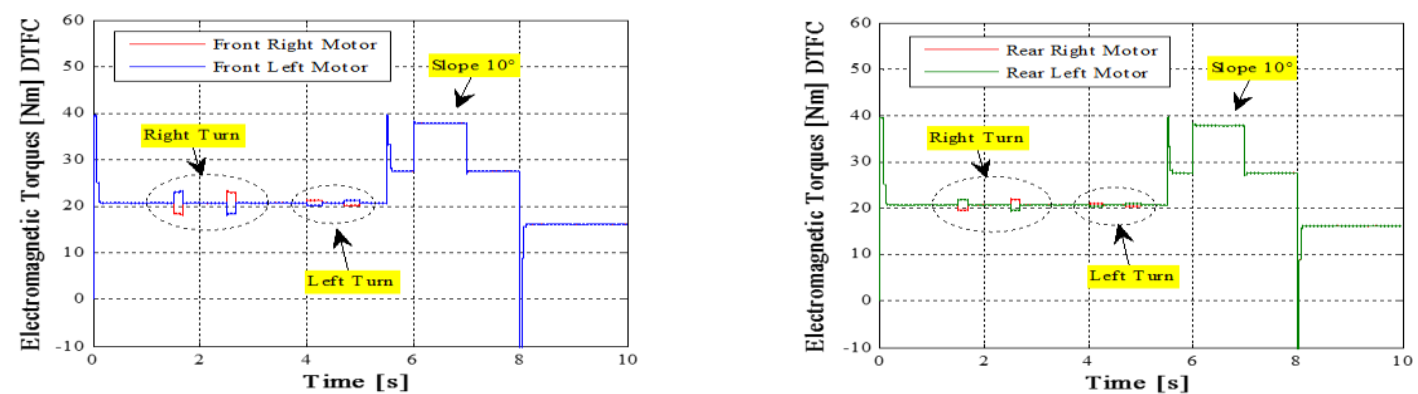

(b)

Figure 13. Electromagnetic torque response developed by the four motors using (a) conventional DTC,

(b) DTFC

Figure 14 (a) and Figure 14 (b) shows the trajectory of the stator flux vector in the plane $(\alpha-\beta)$ related to the stator for the right front (LF) motor. It can be seen that the trajectory of the end of the stator flux in the case of DTFC control (Figure 14 (b)) takes a uniform circular shape with a radius equal to $0.97 \mathrm{~Wb}$ centered at the origin which presents a good decoupling of the flux from the torque. 


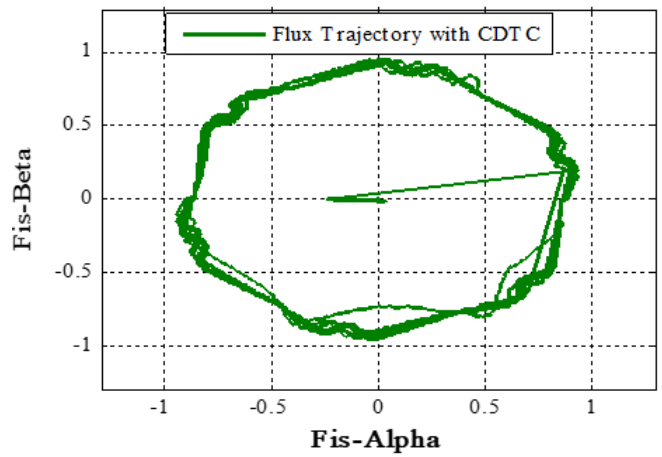

(a)

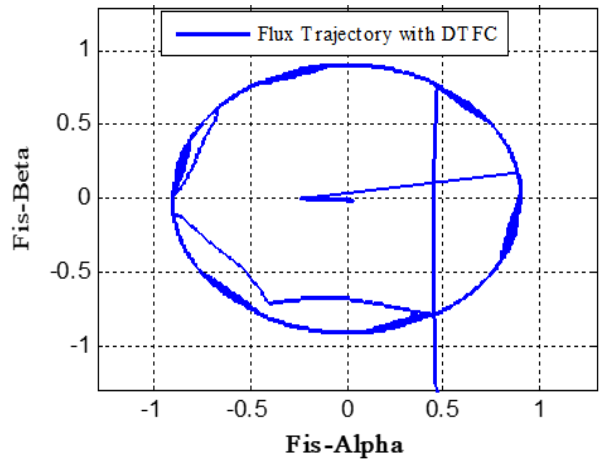

(b)

Figure 14. (a) Trajectory of stator flow in the plane $(\alpha-\beta)$ of the front left engine using classic DTC and

(b) DTFC

\section{CONCLUSION}

In this paper, we have focused on the application of one of the methods of artificial intelligence which is fuzzy logic in a four-wheel drive electric vehicle. after having been able to determine the performance of DTFC compared to DTC, the law of the proposed new control, i.e. DTFC, ensures a good stability of the 4WDEV in different road topologies, curves and slopes and increases the autonomy by reducing consumption of the electric vehicle energy, this was quite clear from the simulation results (MATLAB/Simulink), from which we noticed the reduction of ripples and the rapidity in the torque and flow dynamics during the starting phase of the machine.

\section{ACKNOWLEDGEMENTS}

This work was financially supported by, Smart Grids \& Renewable Energies Laboratory Laboratory, TAHRI Mohammed University of Bechar Algeria and DGRSDT Algeria.

\section{REFERENCES}

[1] A. Hammoumi, Ahmed Massoum and Abdelkader MeroufeLet Patrice Wira, "Application des Réseaux de Neurones pour la Commande de la Machine Asynchrone sans capteur mécanique,"Acta Electrotehnica, vol. 53, no. 2, 2012.

[2] Shubham Pandey, Shubham Chandewar and Krishnamoorthy A, "Smart assisted vehicle for disabled/elderly using raspberry Pi," International Journal of Reconfigurable and Embedded Systems (IJRES), vol. 6, no. 2, pp. 82-87, 2017, doi: 10.11591/ijres. v6.i2.

[3] L. Bounzeki Mbemba., "Modeling, design and experimentation of a light hybrid vehicle for urban use," Doctoral thesis, Specialty: Science for the engineer, Doctoral school for engineering and microtechnology, University of Franche 2012

[4] A. Abbou and H. Mahmoudi, "Performance of a sensorless speed control for induction motor using DTFC strategy and intelligent techniques," Journal of Electrical Systems, vol. 5, no. 3, pp. 64-81, 2009.

[5] M. Depenbrock, "Direct self control of inverter-fed induction machines," IEEE Transaction on Power Electronics, vol. PE-3, no. 4, Oct 1988, doi: 10.1109/63.17963.

[6] I. Takahashi and Y. Omhori, "High-performance direct torque control of an induction motor," IEEE Transaction on Industrial Application, vol. 25, no. 2, pp. 257-264, Mar./Apr. 1989, doi: 10.1109/28.25540

[7] I. Takahashi and T. Noguchi, "Take a look back upon the past decade of direct torque control," IECON. 23rd International Conférence, 9-14 Nov 1997, vol. 2, pp. 546-551, doi : 10.1109/IECON.1997.671792.

[8] A. Ghezouani, "Commande directe du couple par modes glissants (DTC-SMC) d'un véhicule electrique à quatre roues motrice EV4WD,"doctoral thesis, Faculty Science for the engineer, University Tahri Mohamed Bechar, 2019.

[9] Abdelkader Ghezouani, Brahim Gasbaoui, Nouria Nair, Othmane Abdelkhalek and Jemal Ghouil "Comparative study of PI and fuzzy logic based speed controllers of an EV with four in-wheel induction motors drive," Journal of Automation, Mobile Robotics and Intelligent Systems, vol. 13, no. 2, pp. 43-54, Nov 2018, doi: 10.14313/JAMRIS_3-2018/17.

[10] Soufien Gdaim, Abdellatif Mtibaa1, Mohamed Faouzi Mimouni, "Direct torque control of induction machine using fuzzy logic technique,"10th International Conference on Sciences and Techniques of Automatic Control and Computer Engineering, Hammamet Tunisia, December 2009, pp. 1898-1909. 
[11] G. Genta., "Motor vehicle dynamics: modeling and simulation," Series on Advances in Mathematics for Applied Sciences, vol. 43, 1997, doi: 10.1142/3329.

[12] B. Multon, "Motorisation des véhicules électriques,"2001, Dans Techniques de l'ingenieur, numéro E3996.

[13] S. Gdaim, "Commande directe de couple d'un moteur asynchrone à base de techniques intelligentes," Doctoral thesis 2013, Descipline: Science for the engineer; Ecole Nationale d'Ingénieurs de Monastir.

[14] B. Sebti., "Contribution A La Commande Directe Du Couple De La Machine À Induction," doctoral thesis, Specialty: Science for the Engineer, University of Batna, Mars 2011.

[15] Idir Abdelhakim, Kidouche Madjid, Zelmat Mimoune and Ahriche Aimad, "A comparative study between DTC, SVM-DTC and SVM-DTC with PI controller of induction motor," Article Université M'Hamed Bougara de Boumerdès; ICEO'11, pp. 94-97.

[16] S. Kaboli, A. Emadi and M. R. Zolgadhri, "A hysteresis band determination of direct torque-controlled induction motor drives with torque ripple and motor-inverter loss considerations," Power Electronics Specialist Conference, PESC 03. 2003 IEEE, vol. 3, 15-19 June 2003, pp. 1107-1111, doi: 10.1109/PESC.2003.1216604.

[17] Tibor Vajsz, László Számel and György Rácz, "A novel modified DTC-SVM method with better overloadcapability for permanent magnet synchronous motor servo drives," Periodica Polytechnica Electrical Engineering and Computer Science, vol. 61, no. 3, pp. 253-263, 2017, doi: 10.3311/PPee.10428.

[18] A. Maria, "Commande directe de couple à fréquence de modulation constante des moteurs synchrones à aimants permanents," Thèse de Doctorat en Génie Electrique, Institut National des Sciences Appliquées de Lyon, France, Novembre 2004.

[19] Soufien Gdaim, Abdellatif Mtibaa and Mohamed Faouzi Mimouni, "Direct torque control of induction machine based on intelligent techniques," International Journal of Computer Applications, vol. 10, no. 8, Nov. 2010.

[20] A. K. Gautam, S. P. Singh, J. P. Pandey, R. P. Payasi and Anuj Verma, "Fuzzy logic based MPPT technique for photo-voltaic energy conversion system," 2016 IEEE Uttar Pradesh Section International Conference on Electrical, Computer and Electronics Engineering (UPCON), 2016, doi: 10.1109/UPCON.2016.7894665.

[21] C. C. Lee, "Fuzzy logic in control system: fuzzy logic controller Part II," IEEET Ransaction on Systems Man and Cybernetics, vol. 20, no. 2, pp. 419-435, March/April 1990, doi: 10.1109/21.52552.

[22] L. Baghli., "Contribution à la commande de la machine asynchrone, utilisation dela logique floue, des réseaux de neurones et des algorithmes génétiques,"Thèse de Doctorat l’Université Henri Poincaré, Nancy-I, Janvier 1999.

[23] Dan Sun, Yikang He and J.G. Zhu, "Sensorless direct torque control for permanent magnet synchronous motor based on fuzzy logic," Power Electronics and Motion Control Conference, IPEMC 2004, The 4th International, vol. 3, pp. 1286- 1291, 14-16 Aug 2004.

[24] Deng Jinlian and Tu Li, "Improvement of direct torque control low-speed performance by using fuzzy logic technique," Proceedings of the 2006 IEEE, International Conference on Mechatronics and Automation, 25-28 June 2006, Luoyang, China, doi: 10.1109/ICMA.2006.257741.

[25] S. Mir, M. E. Elbuluk and D. S. Zinger, "PI and fuzzy estimators for tuning the stator resistance in direct torque control of induction machines," IEEE Trans. Power Electron, vol. 13, pp. 279-258, 1998, doi: 10.1109/PESC.1994.349655. 